\title{
EXPOSURES AND RISK FACTORS OF CORONA VIRUS AMONG HEALTH CARE WORKERS AND NEED FOR PREVENTIVE MEASURES IN COMBINED MILITARY HOSPITAL RAWALPINDI
}

\author{
Fuad Ahmad Siddiqi, Sobia Mehreen, Adeel Ahmed, Tariq Bashir, Javed Ahmad, Fayyaz Hassan, Fatima Mahmood
}

Combined Military Hospital/National University of Medical Sciences (NUMS) Rawalpindi Pakistan

\begin{abstract}
Objective: Prospective To determine the various risk factors and exposures for spread of Corona Virus Disease 2019 (COVID19) among health care workers working at Combined Military Hospital Rawalpindi.

Study Design: Cross sectional study.

Place and Duration of Study: Combined Military Hospital, Rawalpindi, from Apr to Jul 2020.

Methodology: A total of 134 health care workers who were infected with COVID-19, were included in study. A structured questionnaire was attained after informed consent and approval from hospital ethical committee. Data was analyzed using SPSS-19 statistical software.

Results: Overall, 134 of 2591 Health care workers (Health care workers) in Combined Military Hospital Rawalpindi tested positive for COVID-19 during the study period. The infection rate was 5.17\%. Among them $25(18.7 \%)$ were women and 109 $(81.3 \%)$ were men. There was not statistical difference in infection rate between male and female health care workers $p=0.156)$. The infection rate in clinical category was significantly higher than non-clinical category $(p<0.001$. The infection rate in nursing assistants was significantly higher than the doctors $(p=0.021)$. Personal protective equipment was optimally provided to health care workers except for goggles and face shields whose provision and use were both lacking.

Conclusion: Health care workers are at high risk of developing COVID-19. There is need for extensive training, easy availability of personal protective equipment and strict compliance to infection control policies.
\end{abstract}

Keywords: COVID-19, Health care workers, Risk factors.

This is an Open Access article distributed under the terms of the Creative Commons Attribution License (https://creativecommons.org/licenses/by-nc/4.0/), which permits unrestricted use, distribution, and reproduction in any medium, provided the original work is properly cited.

\section{INTRODUCTION}

COVID-19 spread was first reported in Wuhan China in late December 2019 and January 20201. Since then Corona virus has rapidly spread over many countries. Till 3 July there have been 10,719,946 documented cases with 517,337 deaths world wide ${ }^{2}$.

Corona virus pandemic was declared public heath emergency of international concern on 30 January $2020^{3}$. COVID-19 is a droplet infection but other possible routes of spread are also there including feco-oral, and direct contact. It is also reported to have a long incubation period of 2-14 days ${ }^{4}$. Employing preventive measures to control COVID-19 infection is the corner stone to prevent its spread ${ }^{5}$.

Health care workers are working strenuously day and night with both COVID positive and asymptomatic or suspected COVID cases in wards, emergencies and outpatient departments which places them at high risk of COVID exposure ${ }^{6}$. Combined Military Hospital Rawalpindi is a non COVID Hospital yet our young physicians are ardently managing many newly diagnosed COVID-19 patients daily in emergencies, intensive

Correspondence: Dr Sobia Mehreen, Department of Medicine, Combined Military Hospital, Rawalpindi Pakistan

Received: 07 Aug 2020; revised received: 07 Dec 2020; accepted: 30 Dec 2020 care setting and even in outpatient departments before they are shifted to other health care facilities. They also experience direct contact with patient's attendants who are often asymptomatic undiagnosed COVID-19 cases and often not following the proper preventive measures as required due to unawareness of disease.

Health care workers are rapidly getting afflicted by COVID-19 throughout the world. In Pakistan too health care workers are getting affected due to both known and unknown factors. According to New York Times 35 Health care workers were reported dead and 3600 health care workers were reported affected by corona virus by $15^{\text {th }}$ June 2020 in Pakistan7. The increasing population of affected health care workers not only over burdens the already stressed health care system but also puts their colleagues, patients and families at risk of exposure.

This study aims to inspect the possible exposures and risk factors for COVID-19 among health care workers in order to identify them and recommend measure to curtail spread of COVID-19, so that our already exhausted system does not collapse.

\section{METHODOLOGY}

This cross-sectional study was carried out at Combined Military Hospital Rawalpindi, from April to 
July 2020 on health care workers performing duties in Combined Military Hospital Rawalpindi. Select statistical population proportion sample size calculator was used to calculate sample size with confidence level of $90 \%$, margin of error 5\%, Population size of 2591 and sample proportion of $15 \%{ }^{6}$. All health care workers who were infected with COVID-19 (134) were included in study through nonprobability purposive sampling. They were asked to complete a questionnaire after informed consent and approval from hospital ethics committee certificate no. 88/07/20 (31). High risk health care settings included trauma center, COVID-19 screening desks and wards and intensive care settings dedicated for COVID-19 suspected and positive patients where HCW were directly involved in care of suspected or confirmed COVID-19 patients while low risk settings included general wards, outpatient departments, intensive care settings and Operation theatres for non COVID-19 patients where patients were admitted after extensive screening and clearance along with non-clinical hospital areas The effected individuals were divided into clinical (doctors, nurses and nursing assistants) and non-clinical (ancillary workers) categories. Data was analyzed using SPSS-19 statistical software. Means and standard deviations were measured for numerical variables while frequencies and percentages were measured for categorical variables. Test of significance including chi square test and student t-test were applied on observed differences amongst various groups to assess significance of results.

\section{RESULTS}

Overall, 134 of 2591 HCWs in Combined Military Hospital Rawalpindi were tested positive for COVID19 from $25^{\text {th }}$ April to $11^{\text {th }}$ July 2020 representing an infection rate of $5.17 \%$ (table-I). Of these, $25 \mathrm{HCW}(18.7 \%)$ were women with median age of 27 and $109 \mathrm{HCW}$ $(81.3 \%)$ were male with median age of 28 years. There was not statistical difference in infection rate between male and female HCWs $(p=0.15586)$ (table-II).

Out of $104(77.6 \%)$ of effected HCW worked in settings with low risk of COVID-19 exposure including wards, out patient department (OPD), offices and operation theatres (OTs) and intensive care settings for non COVID-19 patients and $30(22.4 \%)$ of effected HCW worked in settings with high risk of COVID19 exposure including trauma center, screening desks, wards and intensive care settings dedicated for COVID-19 probable or positive patients.

Among the infected HCWs, 24 (17.9\%) were doctors (representing $5.1 \%$ of all doctors at $\mathrm{CMH}$
Rawalpindi), 14 (10.4\%) were nurses (representing $6.42 \%$ of all nurses at CMH Rawalpindi) and 57 (42.5\%) were nursing assistants (representing $10.69 \%$ of all nursing assistants). Remaining 39 (29.1\%) worked in nonclinical settings and were included in ancillary group (representing $2.67 \%$ of all ancillary workers) as shown in table-I.

Out of $62(46.3 \%)$ of the effected were directly involved in patient care of COVID suspected or positive patients. Respiratory procedures were performed by $27(20.1 \%$ of effected HCW $)$ on COVID positive patients as shown in table-II.

Table-I: Basic information of $\mathbf{2 5 9 1}$ health care workers and 134 health care workers with confirmed COVID-19.

\begin{tabular}{|c|c|c|c|}
\hline Characteristics & $\begin{array}{l}\text { Health Care } \\
\text { Workers } \\
\text { with } \\
\text { COVID -19 }\end{array}$ & $\begin{array}{l}\text { Health Care } \\
\text { Workers } \\
\text { without } \\
\text { COVID-19 }\end{array}$ & $\begin{array}{c}p- \\
\text { value }\end{array}$ \\
\hline \multicolumn{4}{|l|}{ Gender } \\
\hline Men & $109(81.3)$ & $1867(76)$ & \multirow{2}{*}{0.156} \\
\hline Women & 25 (18.7) & $590(24)$ & \\
\hline \multicolumn{4}{|l|}{ Job Category } \\
\hline Clinical & 95 & 1037 & \multirow{2}{*}{$<0.001$} \\
\hline Non-Clinical & 39 & 1420 & \\
\hline \multicolumn{4}{|l|}{ Designation } \\
\hline Doctor & $24(17.9)$ & 357 (14.5) & \multirow{2}{*}{0.953} \\
\hline Nurse & 14 (10.4) & $204(8.3)$ & \\
\hline $\begin{array}{l}\text { Nursing } \\
\text { Assistant }\end{array}$ & $57(42.5)$ & 476 (19.4) & 0.021 \\
\hline Ancillary & $39(29.1)$ & $1420(57.8)$ & 0.001 \\
\hline
\end{tabular}

Table-II: Information of 134 health care workers with confirmed COVID-19.

\begin{tabular}{l|c|c}
\hline Characteristics & Yes, n (\%) & No, n (\%) \\
\hline $\begin{array}{l}\text { Personal protective equipment } \\
\text { workshop attended }\end{array}$ & $119(88.8)$ & $13(9.7)$ \\
\hline Involvement in patient care & $62(46.4)$ & $72(53.7)$ \\
\hline Preexisting disease & $11(8.2)$ & $115(85.8)$ \\
\hline $\begin{array}{l}\text { Respiratory procedure } \\
\text { performed on patients }\end{array}$ & $104(77.6)$ & $27(20.1)$ \\
\hline $\begin{array}{l}\text { Identified exposure to COVID } \\
\text { patients }\end{array}$ & $65(51.2)$ & $62(46.3)$ \\
\hline $\begin{array}{l}\text { Transmitted infection to } \\
\text { family members or friends }\end{array}$ & $14(10.4)$ & $109(81.3)$ \\
\hline
\end{tabular}

PPE training workshops were attended by 116 (90.6\%) HCW. A high percentage agreed that surgical masks, N95 masks, gowns, gloves and hand washing were available. Among PPEs the lowest availability was of shield/goggles which was available according to $56.7 \%$ of effected HCWs in COVID susceptible areas and to $33.3 \%$ in unsusceptible areas.

In COVID susceptible areas, N95 mask and gloves were used and hand washing was performed by $100 \%$ 
effected individuals. In COVID unsusceptible areas surgical masks were used and hand hygiene was performed by $>94 \%$ of effected HCWs. In high risk settings shield/goggles were used by only $55.2 \%$ of affected HCW while Donning and doffing practices were strictly followed by $61.5 \%$ of affected HCW in high risk areas. The availability and usage of PPE by affected HCW in COVID susceptible and unsusceptible areas is shown in fig- 1 \& 2 respectively.

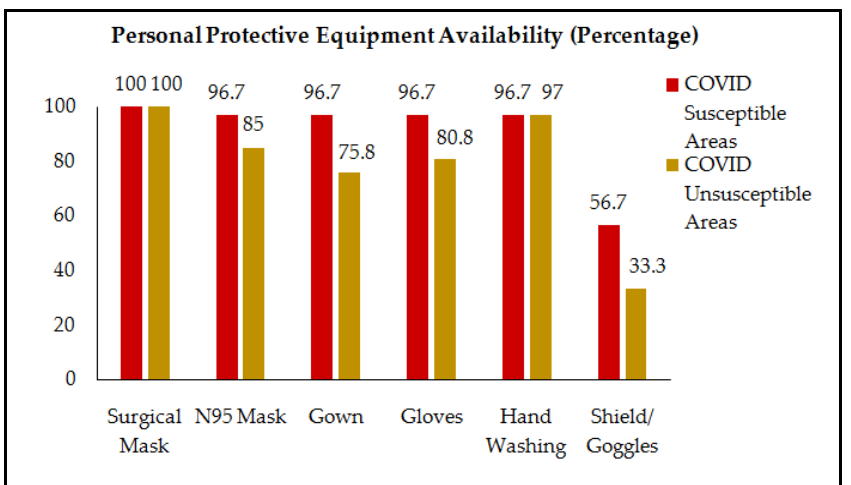

Figure-1: Availability of personal protective equipment at various areas of Combined Military Hospital.



Figure-2: Personal protective equipment usage by effected patients.

Overall, $115(85.8 \%)$ of HCWs with COVID-19 had mild disease, while 13 (9.7\%) HCW described their disease as of moderate severity. None of the health care worker died or developed critical disease. Contact with index patients was described in 49 (36.6\%) and colleagues with infection in $13(9.7 \%)$ of cases. The exposure source could not be identified in about 62 $(46.3 \%)$ cases. Transmission of disease to family and friends was reported in 14 (12.4\%) health care workers.

Median duration of disease symptoms among health care workers was 4 days while median time for first negative PCR was 14 days from onset of symptoms. 115 (85.8\% patients) had no preexisting disease, while $11(8.2 \%)$ patients had one or more preexisting disease (diabetes, asthma, underlying malignancy, heart disease and hypertension).

\section{DISCUSSION}

High level of infection among health care workers with COVID-19 has been documented throughout the world. In China 3.8\% (1716 cases) of all 44672 COVID19 cases till 11 February 2020 were health care workers $^{8}$, and by March about 3300 health-care workers were infected in China with 22 deaths in HCW by the end of February. In Italy, the infection rate among health care workers was still higher, $20 \%$ health-care workers were reported to be infected with COVID in Italy ${ }^{6,9}$. Spain also reported a high level of spread among health care workers with $15 \%$ of total Health care workers being infected by February 20206. Until 4 Dec 2020, the US Centers for Disease Control (CDC) had reported 251498 cases of COVID-19 among HCWs, comprising $11.9 \%$ of all cases; the true number is likely far higher, as only $20.14 \%$ of case reports indicated HCW status ${ }^{10}$.

Various factors are associated with increased COVID risk in Health care workers. A Chinese study reported high-risk department, prolonged working hours, and inadequacy of hand hygiene practice as suggested possible risk associations to COVID-1911. Other factors reported for increased spread among this group includes lack of sufficient scientific knowledge available regarding the mode of spread of COVID and inadequate supplies of appropriate PPE for health care workers due to sudden escalation in global demand 7,12 . The long incubation period of COVID-19 of 2-14 days 4 with median of 5.8 days $^{13}$, and the fact that many patients can be asymptomatic at presentation makes it difficult to early identify patients with disease ${ }^{14}$. These asymptomatic HCW, patients, and patient attendants can in turn lead to increased spread of COVID in hospital facilities Noncompliance with infection control policies and scarcity of provision of proper PPE in low to medium risk departments, could also put HCWs at a higher risk of exposure to COVID ${ }^{15}$.

According to our study, $5.17 \%$ of our health care workers were infected with COVID-19 despite precautionary measures, staff training and segregating hospital in COVID-19 susceptible and non-susceptible areas. This is significantly higher figure when compared to local reported transmission of $0.11 \%$ in Rawalpindi District. i.e. 5815 reported cases of COVID-19 in Rawalpindi district till 2 July 12, 2020 with total speculated population of 5405633 in accordance to 2017 census $^{16,17}$, and transmission rate of COVID-19 in Punjab province 
reported to be $0.078 \%$ i.e. 86556 affected individuals in a population of 110017465 in accordance with 2017 census ${ }^{17,18}$.

A study carried out at Tongi Hospital China in February reported a much lower rate of affected HCW i.e. $1.1 \%$. In this study, the majority $71.8 \%$ were reported female with median age of 36.5 years ${ }^{15}$. While median age of distribution was reported to be 59 years in general population in Wuhan China ${ }^{1}$. Majority of effected HCW in Chinese observation were being nurses $(56.4 \%)$ and physicians $(23.6 \%)$ while 20 health care assistants formed a small part $(20 \%)$. The infection rate was reported lower in first line HCW as compared to other HCW groups, which is in contrast to our findings ${ }^{14}$. Another Chinese study reported median age of distribution of 31 years among HCW and no significant difference in gender distribution, job description or age of HCW ${ }^{11}$.

Majority of patients in our study had only mild symptoms $88.6 \%$ with median duration of symptoms lasting 3 days; this could be explained by the fact that most of the affected health care workers were young with median age of 28 years and did not have comorbidities in $85.4 \%$ cases. The transmission of disease among family members was also less which might be attributed to the fact that many of the health care workers either lived away from families or were quarantined early at diagnosis. The infection rate in clinical category was significantly higher than non-clinical category $(p<0.00001)$ which is likely due to direct exposure of the health care workers in clinical group to COVID patients and attendants consistent with Chinese observation where high risk department HCW had 2.13 times higher risk of COVID-19 than General group $^{11}$.

The infection rate in nursing assistants was significantly higher than the doctors $(p=0.02116)$ in our study which is likely due to better compliance to infection control policies in doctors. It was also found that despite adequate training workshops, availability, and usage of N95 masks, gloves and hand sanitizers, the health care workers followed donning and doffing protocols in only $61.5 \%$ cases in COVID-19 susceptible areas and used goggles and face shields in $55.2 \%$ in COVID-19 susceptible areas. The use of googles in PPE has been shown to be associated with significantly lower incidence of disease spread in a Chinese study carried out on SARS in 2009.(p value0.046) ${ }^{20}$.

Having high clinical index of suspicion for timely identifying COVID-19 in HCW is also essential to prevent its spread in hospitals. By implementing proper policies for infection control and strict adherence to PPE in China, the proportion of HCW with COVID-19 was reduced from $45 \%$ in early January to $9 \%$ in February in China ${ }^{10}$ Use of PPE and adherence to infection control training are linked with reduce infection risk among HCW and improper use of PPE is associated with increased risk ${ }^{11}$.

\section{LIMITATION OF STUDY}

The study is retrospective case series and recall bias can prejudice the outcomes. The study was designed for assessing limited set of risk factors. We did not routinely carry out PCR testing on asymptomatic staff working in high risk setting which might underestimate the actual number of COVID positive health care workers who might be source of infection to their fellow colleagues and patients. More detailed prospective studies will be needed in future to cover all the possible exposures in more detail.

\section{CONCLUSION}

Rapid identification of medical staff with possible infection and routine screening of asymptomatic medical staff could prevent disease spread among HCWs. In order to avoid the increasing spread of COVID-19 among health care workers it is imperative that health care workers are given regular training about proper use of personal protective equipment and emphasized on need of adherence to infection control policies. Readily provision of PPE in workplaces should also be ensured. Emphasis should be placed in proper donning and doffing as well as use of goggles and face shields in high-risk areas.

\section{CONFLICT OF INTEREST}

This study has no conflict of interest to be declared by any author.

\section{REFERENCES}

1. Li Q, Guan X, Wu P, Wang X, Zhou L, Tong Y, et al. Early transmission dynamics in wuhan, china, of novel coronavirus-infected pneumonia. N Engl J Med 2020; 382(13): 1199-1207.

2. COVID-19. WHO Coronavirus Disease (COVID-19) Dashboard, 2020. [Internet] Available from: https://covid19. who.int/?gclid =CjwKCAjw [Accessed 3 July 2020].

3. Euro surveillance Editorial Team Note from the editors: World Health Organization declares novel coronavirus (2019-nCoV) sixth public health emergency of international concern. Euro Surveill 2020; 25(5): 200131e.

4. Backer JA, Klinkenberg D, Wallinga J. Incubation period of 2019 novel coronavirus (2019-nCoV) infections among travelers from Wuhan, China, 20-28 January 2020. Euro Surveill 2020; 25(5): 2000062-66.

5. World Health Organization. Infection prevention and control during health care when novel coronavirus $(\mathrm{nCoV})$ infection is 
suspected. Interim Guidance, 2020. [Internet] Available from: https://www.nih.org.pk/wp-content/uploads/2020/02/ 20200126-ncov-ipc-during-health-care.pdf [Accessed 30 July 2020].

6. Ali S, Noreen S, Farooq I, Bugshan A, Vohra F. Risk Assessment of Healthcare Workers at the Frontline against COVID-19. Pak J Med Sci 2020; 36(COVID19-S4): S99-S103.

7. The New York Times. Pakistan's Lockdown Ended a Month Ago. Now Hospital Signs Read 'Full', 2020 [Internet]. Available from: https://www.nytimes.com/2020/06/15/world/asia/pakistancoronavirus-hospitals.html [Accessed 16 July 2020].

8. Zhi ZLX. Epidemiology working group for NCIP epidemic response, chinese center for disease control and prevention. the epidemiological characteristics of an outbreak of 2019 novel coronavirus diseases (COVID-19) in China. Zhonghua Liu Xing Bing Xue Za Zhi 2020; 41(2): 145-51.

9. The Lancet. COVID-19: protecting health-care workers. Lancet 2020; 395(10228): 922-26.

10. Centers for Disease Control and Prevention (United States). COVID-19 Cases, Deaths, and Trends in the US I CDC COVID Data Tracker, 2020. [Internet]. Available from: https://covid.cdc. gov/covid-data-tracker/\#health-care-personnel [Accessed 5 December 2020].

11. Ran L, Chen X, Wang Y, Wu W, Zhang L, Tan X. Risk factors of healthcare workers with coronavirus disease 2019: A retrospective cohort study in a designated hospital of Wuhan in China. Clin Infect Dis 2020; 71(16): 2218-21.

12. Xiang YT, Jin $Y$, Wang $Y$, Zhang $Q$, Zhang L, Cheung T. Tribute to health workers in China: A group of respectable population during the outbreak of the COVID-19. Int J Biol Sci 2020; 16(10): $1739-40$.
13. McAloon C, Collins A , Hunt K, Barber A, Byrne AW, Butler F, et al. Incubation period of COVID-19: a rapid systematic review and meta-analysis of observational research. BMJ Open 2020; 10(8): e039652-56.

14. Chou R, Dana T, Buckley DI, Selph S, Fu R. Epidemiology of and risk factors for coronavirus infection in health care workers: a living rapid review. Ann Intern Med 2020; 173(2): 120-36.

15. Lai X, Wang M, Qin C, Tan L, Ran L, Chen D, et al. Coronavirus disease 2019 (COVID-19) infection among health care workers and implications for prevention measures in a tertiary hospital in Wuhan, China. J Am Med Assoc 2020; 3(5): e209666.

16. Azeem A. Rawalpindi reports more COVID-19 cases as eight localities go into lockdown 2020. [Internet] Available at: https:/ / www.dawn.com/news/1566424 [Accessed 12 July 2020].

17. Pakistan: Administrative Division. Rawalpindi (District, Pakistan)-Population Statistics, Charts, Map And Location. 2020. [Internet] Available at https://www.citypopulation.de/php/ pakistan-admin.php? adm2id=728 [Accessed 12 July 2020].

18. Punjab-COVID-19 health advisory platform by ministry of national health services regulations and coordination, 2020. [Internet] Available at: http://covid.gov.pk/stats/punjab [Accessed 12 July 2020].

19. Pakistan: Administrative Division. Punjab (Province, Pakistan)Population Statistics, Charts, Map and Location, 2020. [Internet]. Available from: https://www.citypopulation.de/php/pakistanadmin.php? adm1id=7.[Accessed 12 July 2020].

20. Liu W, Tang F, Fang LQ, De Vlas SJ, Ma HJ, Zhou JP. Risk factors for SARS infection among hospital healthcare workers in Beijing: A case control study. Trop Med Int Health 2009; 14(Suppl-1): 52-59. 